DOI: $10.4274 /$ tpa.46.54

\title{
Brain death in children
}

\author{
Burak Tatll, Barış Ekici \\ istanbul University Medical Faculty, Department of Pediatrics Division of Pediatric Neurology, Istanbul, Turkey
}

\begin{abstract}
Summary
Brain death in pediatric patients is an new concept and becoming more important. The definition of brain death is the irreversible cessation of all functions of the entire brain including the brainstem. There are no definitive legal regulations in determining brain death in children as compared with adults. However, small children are more resistant to hypoxic brain damage and can show significant improvements despite the long-term coma. The purpose of this review and checklist for pediatric brain death is to provide a guide for appropriate diagnosis of brain death in children. (Turk Arch Ped 2011; 46: 94-8)
\end{abstract}

Key words: Brain death, brain stem reflex, apnea test

\section{Introduction}

The conventional definition of death is "permanent cessation of cardiac function and respiration". Brain death is defined as irreversible loss of all functions of the brain stem and consciousness (1). The diagnosis of brain death can be made by competent physicians experienced on this subject considering clinical findings and accepted criteria. Brain death in the childhood as well as in adults is a clinical decision based on neurologic examination and is supported by laboratory investigations.

In our country, legal arrangement related to brain death is regulated by the Guide of Organ and Tissue Trasnplantation Services published in the official journal with the number 24066 on 06/01/2000 (2). This regulation specifies the criteria of brain death for adult patients, but it does not involve any arragement for pediatric patients. Increasing numbers of pediatric intensive care beds and transplantations performed in the childhood cause the pediatricians too frequently confront with a decision of brain death. The definition of the presence and determination of medical death was made in the law on transplantation (number 2238) published in 1979 (3). In this law was is stated that medical death is determined by a committee comprising of four physicians (one cardiologist, one neurologist, one neurosurgeon and one anesthesia and intensive care specialist) applying scientific rules and methods at the country's level. Currently, three members of this committee are pediatric cardiologists, pediatrist neurologists and specialists of pediatric intensive care.

\section{Clinical diagnosis of brain death}

The clinical findings in brain death include loss of brain stem functions with coma and unresponsiveness. The brain is more resistant to hypoxic injury in children. Since substantial improvements can be observed despite long-term coma in children, certain differences and difficulties in the diagnosis of brain death are in effect compared to the adults. With these points in mind, the international task force determined the criteria for brain death which can be applied in children in 1987 (4). These criteria include:

1. Determination of the cause leading to brain injury

2. Physicial examination

3. Period of observation and laboratory tests by age groups

Address for Correspondence: Burak Tatlı MD, İstanbul University Medical Faculty, Department of Pediatrics Division of Pediatric Neurology, İstanbul, Turkey E-mail: buraktat@yahoo.com Received: 09.11.2010 Accepted: 09.12.2010 


\section{Physical examination}

Coma and unresponsiveness should be present: The first criterion for brain death is the state of unresponsiveness of the brain where no spontaneous movement or movement triggered by stimulus can be determined. Central body temperature should be above $32^{\circ} \mathrm{C}$. A diagnosis of brain death can not be made in patients with decerebrated or decorticated posture or with movements indicating brain stem activity. On the other hand, spinal chord reflexes including withdrawing the foot when stimulated do not exclude brain death $(5,6)$.

Brain stem reflexes should be absent: Brain stem functions are evaluated by pupil and eye movements, facial sensory and motor responses, pharyngeal-tracheal reflexes and respiration.

1. Dilated and/or fixed pupillae, absence of light reflex

2. Absence of oculocephalic reflex

3. Absence of vestibulo-ocular reflex

4. Absence of cornea reflex, palatal and tracheal reflex

5. Apnea test

1. The pupillae are unresponsive to powerful light and are fixed and dilated $(4-9 \mathrm{~mm})$ in brain death.

2. Oculocephalic reflex can only be evaluated, if there is no fracture or "instability" in the cervical vertabrae. This test is done by moving the head rapidly from the middle line to both sides at $90^{\circ}$ (horizontally) and moving the chin suddenly up and down (vertically). In the decubitus position, semicircular canals of the labyrinth and deep sensory receptors of the cervical muscles are stimulated by the turning movement of the head. In unconscious patients, eye movements due to the turning of the head are only related to the "semicircular" canals being affected. In healthy individuals, the eye move towards the opposite side where the head has been turned and then slowly come back to the initial position. However, horizontal and vertical movements of the eyes are absent in brain death; the eyes move in the same direction as the head and no eye movement is observed in the orbitae.

3. Vestibulo-ocular reflex is tested by washing both ears with at least $20 \mathrm{ml}$ icy water after elevating the head of the patient at $30^{\circ}$. However, it should be checked if the tympanic membranes are intact and external auditory canal are obliterated or not before the test. Normally, the eyes move towards the side which has been washed. In brain death, this movement is not observed. For an accurate result, observation should be done for 1 minute after the water is given and the test in the second ear should be done 5 minutes after the first ear.

4. Examination of facial sensory and motor responses:

a) Absence of blinking movement when the cornea is touched with cotton (cornea reflex)

b) Absence of jaw reflex (when the chin is tapped with a finger a response of chewing occurs)

c) When deep compression is applied on the nail fold or on the supramandibular or temporomandibular joint, absence of wrinkling and grimace in the face.

5. Apnea test: The most important brain stem reflex is the regulation of respiration. Loss of brain stem function causes apnea with loss of respiration and vasomotor control. Therefore, the apnea test is very important in evaluating brain functions. Some prerequisites are in effect to perform the apnea test (7).

a) The body temperature should be above $35.5^{\circ} \mathrm{C}$

b) Systolic blood pressure should be higher than 90 $\mathrm{mmHg}$

c) Hypovolemia should not be present

d) $\mathrm{PaCO}_{2}$ and $\mathrm{PaO}_{2}$ values should be normal (preferably $\mathrm{PaCO}_{2}$ should be $40 \mathrm{mmHg}$ and higher initially, the patient should be ventilated with $100 \% \mathrm{O}_{2}$ for $10-30$ minutes before the test and $\mathrm{PaO}_{2}$ should be increased above 20 $\mathrm{mmHg}$ )

After these conditions are fulfilled, peripheral $\mathrm{O}_{2}$ saturation of the patient is monitored with devices and the patient is seperated from the ventilator. $100 \% \mathrm{O}_{2}$ is applied at $6 \mathrm{~L} / \mathrm{min}$ with a canulla placed into the trachea or preferably until the superior part of the carina by endotracheal tube or tracheostomy cannula (apneic oxygenation). A careful observation is made to see if abdominal or chest movements providing adequate "tidal" volume are present or not. Different sudies have reported that $\mathrm{Pa} \mathrm{CO}_{2}$ increases $1-3 \mathrm{mmHg}$ per minute by apneic oxygenation and $\mathrm{PaCO}_{2}$ usually reaches $60 \mathrm{mmHg}$ at the end of 8 minutes. Therefore, blood sample to measure blood gases is taken approximately 8 minutes later and the patient is attached to the ventilator. If $\mathrm{PaCO}_{2}$ is $60 \mathrm{mmHg}$ or higher and respiratory movements are absent, the apnea test is positive and this finding supports brain death. If respiratory movements are observed, the test is negative and should be repeated. If $\# \mathrm{PaCO}_{2}$ is lower than $60 \mathrm{mmHg}$, the patient is seperated from the ventilator for 10 minutes and the test is repeated. However, spinal reflex movements which do not provide adequate tidal volume should be differentiated form spontaneous respiratory movements during the test (8).

If systolic blood pressure decreases below $90 \mathrm{mmHg}$ or $\mathrm{O}_{2}$ desaturation developes $\left(\mathrm{O}_{2}\right.$ saturation lower than $\left.90 \%\right)$, blood sample to measure blood gases is obtained immediately and the patient is attached to the ventilator. If $\mathrm{PaCO}_{2}$ is $60 \mathrm{mmHg}$ or higher, the apnea test is again positive. However, if $\mathrm{PaCO}_{2}$ is below $60 \mathrm{mmHg}$, supportive tests should be performed. Hypoxia developes frequently during the apnea test and may lead to organ injury. Providing adequate oxygenation during the test may be rather difficult especially in patients with severe respiratory failure (adult respiratory distress syndrome (ARDS), chronic obstructive lung disease, bronchiectasis etc.). Therefore, $\mathrm{O}_{2}$ with continious positive pressure $\left(10 \mathrm{~cm} \mathrm{H}_{2} \mathrm{O}\right)$ may need to be given to patients with respiratory failure during the apnea test.

It is not known at which $\mathrm{PaCO}_{2}$ level the receptors in the respiratory center are stimulated (in hyperoxygenated patients and in patients with brain injury). However, to stimulate the brain stem at the highest level, $\mathrm{PaCO}_{2}$ is generally recommended to be kept $60 \mathrm{mmHg}$ and higher. In patients with chronic hypercapnia, target $\mathrm{CO}_{2}$ level for the apnea test may be higher and additional supportive tests may be needed for diagnosis of brain death in these patients (9). 
Atropine test can be performed in addition to the apnea test. If an increase of more than $10 \%$ in heart rate does not occur after administering $2 \mathrm{mg}$ atropin IV, the test is positive and it supports the diagnosis of brain death.

The patient should not be hypothermic and hypotensive.

Flaccid tonus, spontaneous movement other than spinal chord movements should be absent.

Clinic findings should not change during the observation period.

\section{Observation period and laboratory tests by age groups}

a. 7 days-2 months: 2 clinical evaluations and 2 encepahlograms (EEG) with an interval of 48 hours

b. 2 months- 1 year: Two clinical evaluations and two EEG's at least 24 hours apart or two clinical evaluations and inital EEG showing electrocerebral silence with cerebral angiography confirming that brain blood flow has ceased

c. >12 months: Two clinical evaluations 12-24 hours apart. Encephalogram and isotope angiography are optional. In hypoxic ischemic encephalopathy, observation peroid should be 24 hours.

For a dignosis of brain death, disorders of electrolyte and acid-base balance and endocrine disorders which may mimic the clinical picture of brain death should be excluded. Before the diagnosis, intoxication, hypothermia, use of sedative analgesics and neuromuscular blocking agents which may cause this clinic picture should be excluded.

In some patients diagnosed as brain death, spontaneous and reflex movements may be observed. However, this may cause suspicion about the diagnosis both in the relatives of the patient and in the healthcare team. The cells which cause these muscle movements are not found in the brain or brain stem, but they are the neurons found in the spinal chord. These reflex movements include finger movements, repeated toe flexion, plantar flexor response, unilateral facial muscle vibrations, Lazarus sign, rocking motion of the head, extension posture of the upper extremities, knee reflex, withdrawal of the ankle, abdominal reflex and ciliospinal response. Spontaneous movements of the extremities other than pathologic flexion or extention may include elevation and adduction of the shoulder, back arching, intercostal expansion, sweating, flushing, tachycardia, normal or increased blood pressure, deep tendon reflexes and Babinsky reflex (6).

If there is a suspicion about the primary cause of brain injury, reversible causes of coma are considered, clinical tests can not be well evaluated or the apnea test can not be performed due to development of hypoxia, some supportive tests may be performed.

1. Electrophysologic evaluations (EEG, sensory evoked potentials, etc.)

2. Brain blood flow measurements (angiography, transcranial doppler USG, etc.)

3. Brain metabolism measurements (metabolic rate of oxygen in the brain, jugular venous saturation, etc.).

4. Pathomorphologic measurements (computarized tomography of the brain (CTB), magnetic resonance imaging, etc.)

5. Atropine test

Encephalogram gives us information about the brain cortex, but not about the brain stem. In additon, it is not a very reliable method because of the difficulty in obtaining a healthy line due to excess electrical equipment in intensive care units and false negative line in cases like hypothermia (10). Encephalogram findings can not solely make a diagnosis of brain death. However, it may help to make the diagnosis together with different methods in required cases. When used in combination with clinical evaluation and other tests, EEG is significant in terms of indicating brain death. The following techical conditions must be fulfilled (11).

- At least 8 scalp electrodes should be used.

- Inter-electrode resistance should be between 100 and $10000 \Omega$

- The integrity of the recording system should be tested.

- Inter-electrode distance should be at least $10 \mathrm{~cm}$.

- Sensitivity should be increased at least to 2 microvolt in 30 minutes and appropriate arrangement should be done.

- High frequency filter adjustment should not be lower than $30 \mathrm{~Hz}$ and low frequency adjustment should not be higher than $1 \mathrm{~Hz}$.

- Encephalogram should display unresponsiveness to powerful somatosensory or audiovisual stimuli.

Currently, the opinion that brain stem evoked potential records should be preferred over EEG to support the diagnosis of brain death is becoming predominant (12). Among the available methods, the best opinion about brain stem neuron activity is obtained by examination of responses to stimuli given to the neurons of the cochlear nerve in the brain stem. This test which is based on recording of waves appearing in the auditory ways in the brain stem after the ear is given a stimulus of a certain decibel can easily be performed at bedside and no significant difficulty is faced in evaluating the recordings. In addition, it is insensitive against the effects of barbiturates and other central nervous system depressants. While brain stem auditory evoked responses are being recorded, the following conditions should not be present: a previos pathology in the cochlear conduction way, traumatic laceration of the 8th nerve, pontine bleeding or history of a surgical intervention in the posterior fossa (13). Since a negative result may be erroneous in such cases, it is mandatory to use another test.

The most accurate information indicating brain death is obtained by showing that brain blood flow is absent. As the circulation continues in the external carotis artery, blood flow after the cranial base in the internal carotis artery is ceased because of increased intracranial pressure and cerebrovascular autoregulation. There are different methods used to measure brain blood flow. However, clinical and technical properties of each of these methods should be well known. For example, "conventional" 4-vessel angiography requires that the patient is transported to the radiology unit and its performance takes a long time. It will also be misleading in cases of subintimal injection or arterial thrombosis, since it will be observed that 
brain blood flow is absent. In addition, timing of the graphy with injection of contrast material should be well done. It should be kept in mind that repeated injections of contrast material may cause a risk of nephrotoxicity and the known histotoxic effect of the contrast material injected intraarterially especially on injuried brain tissue may lead to additional injury in a patient who may have a chance of survival (14).

Single photon emission computerized tomography (SPECT) is considered to be more reliable in determining cerebral blood flow and cerebral perfusion compared to conventional 4-vessel angiography.

Radionuclide angiography performed using xenon and technetium-99 is not reliable for evaluation of posterior fossa and brain stem blood flow. Therefore, radionuclide scintigraphy performed using Tc-HMPAO which crosses blood-brain barrier is recommended (15).

Radionuclide tests are non-invasive and reliable methods which can be used to determine brain death. The disavantage of these methods is the requirement of transportation of the patient to the division of nuclear medicine.

Transcranial doppler ultrasonography (TDU) is a valuable test giving information about brain circulation. With this method, information about the flow of both carotid arteries and the basilar artery can be obtained. This method has advantages including noninvasiveness, rapid application, portability and relatively low price. Its specificity and sensitivity has been reported to be $91-100 \%$ (16). To minimize false positive results with this method both anterior and posterior circulation should be tried to be displayed in both hemispheres. Transcranial doppler ultrasonography should be performed, if systolic blood pressure is above $100 \mathrm{mmHg}$.

There are limited number of publications about brain death in term and preterm newborns and criteria are more controversial compared to other age groups. For a diagnosis of brain death in term babies with a postgestational age of 7 days-2 months, it is mandatory to use 2 clinical evaluations performed at least 48 hours apart and supportive laboratory tests. Currently, application of clinical evaluation in preterm babies is being debated. Since findings related to the brain stem have not yet developed especially in very small birth weight babies, it is not possible to evaluate their absence (17) (light reaction may appear at the 30-32nd gestational week, oculocephalic response may appear at the 28-32nd gestational week, sucking-rooting reflex and gag reflex may appear at the 32-34th gestational week).

The decision of brain death is rather controversial in anencephalic newborns. As known, higher cortical structures are not developed, but the brain stem functions in these babies. Therefore, current criteria of brain death can not be applied to these children.

The process of diagnosing brain death is being questioned also in developed countries and it is thought that compliance with the criteria is low. In the study performed by Mudit et al. (18) in USA in 2007, in only $18 \%$ of the patients older than 1 years of age, appropriate intervals were found between clinical evaluations and the apnea test was not performed in $60 \%$ of the patients. These findings emphasize the need for a checklist which will remind the physicians the steps in the process of the decision of brain death. In two large children's hospitals in England, using a checklist which involves local criteria in practice increased the rates of appropriate decisions of brain death from $50 \%$ to $90 \%$ (19).

As İstanbul University Medical Faculty Department of Pediatric Neurology, we contribute to the decision-making process for brain death in children in our university where organ transplantation is being performed intensively since 2005. We think that obviating lack of information on this area and efficient decision making will increase the number of organ transplantation

\section{References}

1. A definition of irreversible coma. Report of the Ad Hoc Committee of the Harvard Medical School to Examine the Definition of Brain Death. JAMA 1968; 205: 337-40.

2. Organ ve Doku Nakli Hizmetleri Yönetmeliği T.C. Resmi Gazete 24066 01/06/2000.

3. 2238 sayılı Transplantasyon Kanunu T.C. Resmi Gazete 16665 03/06/1979.

4. American Academy of Pediatrics Task Force on Brain Death in Children. Report of special task force: guidelines for the determination of brain death of children. Pediatrics 1987; 80: 298-300.

5. Han SG, Kim GM, Lee KH, Chung CS, Jung KY. Reflex movements in patients with brain death: a prospective study in a tertiary medical center. J Korean Med Sci 2006; 21: 588-90.

6. Saposnik G, Bueri JA, Mauriño J, Saizar R, Garretto NS. Spontaneous and reflex movements in brain death. Neurology 2000; 54: 221-3.

7. Yee AH, Mandrekar J, Rabinstein AA, Wijdicks EF. Predictors of apnea test failure during brain death determination. Neurocrit Care 2010; 12: 352-5.

8. Lang CJ, Heckmann JG. Apnea testing for the diagnosis of brain death. Acta Neurol Scand 2005; 112: 358-69.

9. Tibballs J. A critique of the apneic oxygenation test for the diagnosis of "brain death. Pediatr Crit Care Med 2010; 11: 475-8.

10. Meinitzer A, Kalcher K, Gartner G, Halwachs-Baumann G, März W, Stettin M. Drugs and brain death diagnostics: determination of drugs capable of inducing EEG zero line. Clin Chem Lab Med 2008; 46: 1732-8.

11. Alvarez LA, Moshé SL, Belman AL, Maytal J, Resnick TJ, Keilson M. EEG and brain death determination in children. Neurology 1988; 38: 227-30.

12. Ruiz-López MJ, Martínez de Azagra A, Serrano A, Casado-Flores J. Brain death and evoked potentials in pediatric patients. Crit Care Med 1999; 27: 412-6.

13. Firsching R, Frowein RA, Wilhelms S, Buchholz F. Brain death: practicability of evoked potentials. Neurosurg Rev 1992; 15: 249-54.

14. Quesnel C, Fulgencio JP, Adrie C, et al. Limitations of computed tomographic angiography in the diagnosis of brain death. Intensive Care Med 2007; 33: 2129-35.

15. Conrad GR, Sinha P. Scintigraphy as a confirmatory test of brain death. Semin Nucl Med 2003; 33: 312-23.

16. Monteiro LM, Bollen CW, van Huffelen AC, Ackerstaff RG, Jansen NJ, van Vught AJ. Transcranial Doppler ultrasonography to confirm brain death: a meta-analysis. Intensive Care Med 2006; 32: 1937-44

17. Gotay-Cruz F, Fernández-Sein A. Pediatric experience with brain death determination. P R Health Sci J 2002; 21: 11-5.

18. Mudit M, LuCyndi $P$, Maria S, et al. Variability in pediatric brain death determination and documentation in Southern California. Pediatrics 2008; 121: 988-93.

19. Kafrawy U, Stewart D. An evaluation of brainstem death documentation: the importance of full documentation. Paediatr Anaesth 2004; 14: 584-8. 


\section{CHECKLIST FOR BRAIN DEATH IN CHILDREN}

This checklist is prepared based on the report of special task force (Guidelines for the determination of brain death in children. Pediatrics Aug 1987; 80 (2): 298-300). The decision of brain death is made by two evaluations performed by two different physicians at different times. (Please mark)

\begin{tabular}{|l|c|c|}
\hline The time which should pass between the two evaluations according to the patient's age & In brain injury excluding anoxia & Anoxic brain injury \\
\hline 7 days- 2 months old & At least 48 hours & At least 48 hours \\
\hline 2 months-12 months old & At least 24 hours & At least 24 hours \\
\hline Older than 1 year & At least 12 hours & At least 24 hours \\
\hline
\end{tabular}

\section{Determination of the patient's compatibility for evaluation of brain death}

\section{A. Reason of irreversible coma}

Traumatic brain injury Anoxic brain injury Known metabolic disease

B. Presence of conditions which may effect the evaluation

Body temperature $<35.5 \mathrm{C}$

Blood pressure by age $<2$ SD

Drug intoxication or paralysis, metabolic disorder1

At least 24 hours

\begin{tabular}{|c|c|c|c|c|}
\hline \multirow{2}{*}{$\begin{array}{l}\text { Physical examination } \\
\text { Note: Spinal reflexes are excluded from the evaluation } \\
\text { Flaccid tonus, the patient is not responsive to painful stimuli. }\end{array}$} & \multicolumn{2}{|c|}{ First evaluation } & \multicolumn{2}{|c|}{ Second evaluation } \\
\hline & Yes & No & Yes & No \\
\hline Pupillae are dilated, light reflex is absent. & Yes & No & Yes & No \\
\hline Cornea, cough, gag, sucking and rooting reflexes are absent. & Yes & no & Yes & No \\
\hline $\begin{array}{l}\text { Oculovestibular reflex is absent. (although at least } 20 \mathrm{ml} \text { cold } \\
\text { water is given into the external auditory meatus following } \\
\text { confirmation of intact tympanic membranes) }\end{array}$ & Yes & No & Yes & No \\
\hline Oculocephalic reflex is absent. & Yes & No & Yes & No \\
\hline Brain and brain stem functions are lost irreversibly. & Yes & No & Yes & No \\
\hline Spontaneous respiration effort is absent. & Yes & No & Yes & No \\
\hline On physical examination & \multicolumn{4}{|c|}{$\begin{array}{l}\text { (specify) can not be evaluated, (reason), } \\
\text { therefore EEG or cerebral flow has been performed }\end{array}$} \\
\hline APNEA test ${ }^{2}$ & \multicolumn{2}{|c|}{ First evaluation } & \multicolumn{2}{|c|}{ Second evaluation } \\
\hline Apne testinde spontan solunum hareketi gözlenmedi & \multicolumn{2}{|c|}{$\begin{array}{l}\text { Pre-test } \mathrm{PaCO}_{2}: \\
\text { Pre-test } \mathrm{PaCO}_{2} \text { : }\end{array}$} & \multicolumn{2}{|c|}{$\begin{array}{l}\text { Post-test } \mathrm{PaCO}_{2} \text { : } \\
\text { Post-test } \mathrm{PaCO}_{2}:\end{array}$} \\
\hline
\end{tabular}

Apnea test is contraindicated or can not be completed (reason): Therefore EEG or cerebral flow test has been performed.

\begin{tabular}{|c|c|c|c|c|}
\hline $\begin{array}{l}\text { Supportive tests (Although not mandatory in children younger than } 1 \text { years of age, } \\
\text { supportive tests may be used in cases where observation time is desired to be shortened) }\end{array}$ & \multicolumn{2}{|c|}{ First evaluation } & \multicolumn{2}{|c|}{ Secnd evaluation } \\
\hline Shows electrocerebral silence on EEG. & Yes & No & Yes & No \\
\hline Cerebral circulation could not be found on cerebral blood flow test 3 . & Yes & No & Yes & No \\
\hline \multicolumn{5}{|l|}{ First evaluation } \\
\hline $\begin{array}{l}\text { My evaluation shows that brain and brain stem functions are absent. Second evaluation is } r \\
\text { (Name-Surname) } \\
\text { (Speciality) } \\
\text { (Digna } \\
\text { (Date) }\end{array}$ & dired. & (Time) & & \\
\hline \multicolumn{5}{|l|}{ Second evaluation } \\
\hline $\begin{array}{l}\text { My evaluation shows that brain and brain stem functions are absent and brain death has occ } \\
\text { Date and time of death: } \\
\text { (Name-Surname) } \\
\text { (Speciality) }\end{array}$ & ed. & & & \\
\hline
\end{tabular}

1. Drug intoxication or metabolic intoxication: All sedative drugs should be discontinued before the evaluation of brain death before 4 times the half-life of the drug. Drug intoxications which may cause coma should be excluded. Metabolic disorders should be corrected before evaluation.

2. Apnea test: Before the test ventilation with $100 \% \mathrm{FiO}_{2}$ oxygen is performed and blood sample is taken to measure blood gases. The patient is seperated from the ventilator and 4-12 L/min oxygen is given for 5-10 minutes endotracheally or by ventilator on CPAP mode. Spontaneous respitation movement is searched for during the test period. The test is ended by obtaining blood sample for blood gases. If hypotension, severe hypoxia or arythmia developes, the test is stopped immediately. In the conforming apnea test, respiration movement should not have been observed during the test, in the second measurement of blood gases, $\mathrm{PCO}_{2}$ should be $>60 \mathrm{mmHg}$ or should be $20 \mathrm{mmHg}$ higher than the first measurement.

3. Cerebral blood flow: Absence of cerebral blood flow is shown by radionuclide screening or 4 artery angiography. These tests can be used to determine brain death in metabolic or drug-related comas 